stichting

mathematisch

centrum

MC

AFDELING INFORMATICA

(DEPARTMENT OF COMPUTER SCIENCE)

IN $19 / 81 \quad$ JANUARI

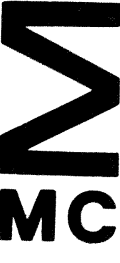

AFDELING INFORMATICA
(DEPARTMENT OF COMPUTER SCIENCE)

A.C. VELDKAMP, T. HAGEN \& J.D. VAN DER WOUDE

LASER PLOTTING OF POLLEN DIAGRAMS

kruislaan 4131098 SJ amsterdam 
Printed at the Mathematical Centre, 413 Kruislaan, Amsterdam.

The Mathematical Centre, founded the 11-th of February 1946, is a nonprofit institution aiming at the promotion of pure mathematics and its applications. It is sponsored by the Netherlands Government through the Netherlands Organization for the Advancement of Pure Research (Z.W.O.). 


\section{LASER PLOTTING OF POLLEN DIAGRAMS}

by

A.C. Veldkamp, T. Hagen \& J.D. van der Woude

\section{ABSTRACT}

Computer drawing of pollen diagrams of any size can be done with extreme accuracy by using a laser plotter. A short outline of the techniques and the program used is given, together with an example of a laser plotted diagram.

KEY WORDS \& PHRASES: 1aser plotter, pollen diagram 


\section{INTRODUCTION}

Most published pollen diagrams, and diagrams of other paleobiological data as well, are still drawn by hand. With the increasing amount of data to be published, drawing of pollen diagrams is nowadays a very laborious task. This increase is mainly due to the steadily improving precision of the analyses, which is achieved mainly by taking a smaller sampling interval in the vertical sections and also by differentiation of the analyzed taxa. In many cases drawing of the complete diagrams has already become too laborious. Also, hand drawing of pollen diagrams suffers from technical problems. Especially the precise representation of small values is difficult.

The advantages of drawing pollen diagrams by means of a computer are obvious. After finishing the pollen analysis the diagram can be available within a short time for both interpretation and publication. When additional or different data become available afterwards or if the composition of the pollen sum should be changed, the diagram can easily be redrawn. The availability of pollen data in computer readable form not only facilitates the drawing (plotting) of the diagram, but several computations as well.

Earlier papers on techniques for computer drawing of pollen diagrams are not reviewed here. However, in general one may state that the highly mechanical nature of the conventional plotting techniques will of ten cause deviations in the lines drawn or irregularities in the supply of ink. Probably these problems will yet be solved rather satisfactorily.

\section{TECHNIQUES}

With the new method presented here, the pollen diagrams are drawn with a laser plotter. The diagrams are actually drawn with a laser beam on film instead of with ink on paper.

The basic advantage of a laser plotter is that very fine lines can be drawn with extreme accuracy. Positioning of the beam is achieved with the aid of a system of movable mirrors. The motion of the mirrors is controlled by a computer. This ingenious construction makes it possible to manipulate the laser beam. The actual drawing is made on a photographic film of 10 by $15 \mathrm{~cm}$. When the drawing is finished this microfiche is available for further photographic processing.

In the introduction some drawbacks of the commonly used methods of drawing a diagram were summed up. With the laser plotting techniques these drawbacks are eliminated, and we gain a lot of advantages besides. First of all, the drawing speed is very high. Secondly, the diagrams are drawn on a microfiche which has a very convenient format. In practice a microfiche can easily contain a diagram of a thousand depth samples and a total width of about 1500 percent. For larger diagrams several microfiches have to be used. Thirdly, the accuracy of the diagrams drawn 
is very high, mainly because of the fact that the diameter of the light beam is smaller than the granule width of the photographic emulsion. So the accuracy is mainly limited by the photographical properties of the used film. Finally, microfiches can be excellently reproduced.

Thus far we have only sketched the application of the computer as a controlling device of the laser plotter. In addition to this, the computer can be used to deal with the high amount of input data. One possibility is to do some statistics on these data in order to get an idea about their reliability.

\section{PROGRAM}

A computer program to plot pollen data with a laser plotter has been developed at the Mathematical Centre. The main features of this program will be briefly discussed here.

When the counted pollen data are fed into the computer, the pollen values may be given in percentages or in absolute figures (leaving, if desired, the transformation into percentages to the program). Zero values can be left out. Alterations and additions to the data input are always possible afterwards, for example when a follow-up study is undertaken.

After they have been read in the data are checked for inconsistencies. These may be related to the sequence of the samples, non-existing index-numbers of pollen taxa, or doubling of pollen taxa in a sample.

Next a statistical survey is printed, showing per taxon: indexnumber, name of the taxon, total number of positive values, maximum value, sample depth of maximum value, average value of all samples, and the average value of positive samples. This enables the palynologist to decide on the possible omission of some taxa and on the maximum width of the histogram per taxon. The latter is needed also for cutting off high peaks in the curves. This can be effectuated in two ways:

1. Only the shading of the peaks is cut off (see Fig.1, Umbelliferae), or 2. Within the shaded histogram a second curve is drawn, showing one tenth of the real values (Fig. 1, Bryophyta).

The final step, the plotting of the diagram, consists of the drawing of the curves, shading, depth-scale, the marking of sample depths, and the drawing of the names of the taxa and the percentage-scale (see Fig.1). This basic form will suffice for most purposes. As the program is rather flexible, special wishes can easily be met, e.g. inclusion of a composite summation diagram or Iversen symbol curves.

Requests for the laser plotting of pollen diagrams can be sent to the first two authors. 


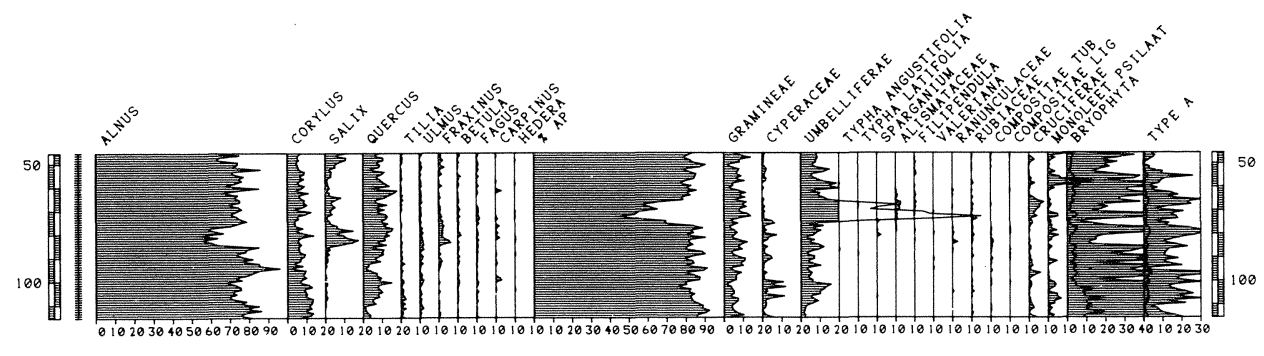

Fig.1. Example of laser plotted pollen diagram. Selected curves from the topmost part of a pollen section in the fluvial coastal plain of the Western Netherlands (near Molenaarsgraaf, prov. of South-Holland; from a publication in prep. by the third author) The shown section consists completely of woodpeat, belonging to the so-called Surface Peat of the Western Netherlands. The woodpeat accumulated during the late Subboreal and early Subatlantic in an alder swamp. On a nearby sand stretch (the filling of a former river course) was an oak stand, bordered by ash and elm at the transition to the alder swamp. In the middle part of the section, decrease of the values of Alnus and increase of the values of Salix, Umbelliferae, Alismataceae and Cruciferae point to a more open character of the alder swamp. This may be related to a temporary increase in the rise of the local water level. 
